Elsevier required licence: (C) <2021>. This manuscript version is made available under the CC-BY-NCND 4.0 license http://creativecommons.org/licenses/by-nc-nd/4.0/

The definitive publisher version is available online at

[https://www.sciencedirect.com/science/article/abs/pii/S030626192100636X?via\%3Dihub] 


\title{
Application of biogas recirculation in anaerobic granular sludge system for multifunctional sewage sludge management with high efficacy energy recovery
}

\author{
Jiamin Zhao a, Tingting Hou ${ }^{\mathrm{a}}$, Qian Wang ${ }^{\mathrm{a}}$, Zhenya Zhang ${ }^{\mathrm{b}}$, Zhongfang Lei ${ }^{\mathrm{b}}$, Kazuya Shimizu ${ }^{\mathrm{b}}$, \\ Wenshan $\mathrm{Guo}^{\mathrm{c}}$, Huu Hao $\mathrm{Ngo}^{\mathrm{c}}$ \\ ${ }^{a}$ Graduate School of Life and Environmental Sciences, University of Tsukuba, 1-1-1 Tennodai, Tsukuba, \\ Ibaraki 305-8572, Japan \\ ${ }^{b}$ Faculty of Life and Environmental Sciences, University of Tsukuba, 1-1-1 Tennodai, Tsukuba, Ibaraki \\ 305-8572, Japan \\ ${ }^{c}$ Centre for Technology in Water and Wastewater, School of Civil and Environmental Engineering, \\ University of Technology Sydney, NWS 2007, Australia \\ *Corresponding author.E-mail address: lei.zhongfang.gu@u.tsukuba.ac.jp (Z. Lei).
}

\begin{abstract}
This study investigated the possibility of biogas recirculation-driven anaerobic granular sludge system for sewage sludge treatment, aiming to develop an energy sufficient and multifunctional anaerobic digestion (AD) system for sewage sludge with biogas upgrading, sludge stabilization and self-aggregation. Results show that biogas recirculation could enhance the $\mathrm{CH}_{4}$ production rate by $31-44 \%$ and shorten the lag-phase duration to $0.08-0.2$ day with simultaneous increment of $\mathrm{CH}_{4}$ content ( $>83 \%$ in this study). The reason is mainly associated with the stronger interspecies electron transfer under the biogas recirculation condition. In addition, 37-40\% better dewaterability of the digested sludge was achieved, implying the occurrence of self-aggregation of microbial cells induced by biogas recirculation. Energy balance analysis reflects that this sewage sludge treatment system could enhance the net energy recovery by $78-85 \%$. Moreover, almost no obvious influence was noticed on the seed granules' composition and properties. These findings suggest that the biogas recirculation-driven anaerobic granular sludge system could be a promising alternative for sewage sludge treatment, which can improve biogas quality and sludge dewaterability simultaneously towards sludge self-aggregation with no addition of other chemicals.
\end{abstract}

Keywords: Sewage sludge; Up-flow anaerobic granular sludge system; Biogas recirculation; Energy recovery; Sludge dewaterability

\section{Introduction}

The production of sewage sludge, i.e., the major by-product from wastewater treatment, is increasing globally along with the stringent requirements for wastewater treatment plants (WWTPs). Nowadays, sewage sludge is treated and/or disposed mainly through landfilling, recycling as building materials, and biogas production via anaerobic digestion (AD). Sludge-toenergy systems have been widely recognized as a favorable technology for sewage sludge management and energy recovery [1]. Taking Japan as an example, about $24 \%$ of sewage sludge has been re-utilized as biomass energy (16\% biogas $+8 \%$ sludge fuel) in 2019 [2]. Energy from renewable wastes is of great concern and popularity to overcome the global energy crisis. AD of sewage sludge can simultaneously achieve energy recovery (mainly as $\mathrm{CH} 4$ ), solid content 
reduction, sludge stabilization, pathogens removal, and odor emissions reduction that can ease its final and safe disposal [3]. Up to now, although AD has been widely applied in WWTPs for decades, such problems as the large reactor volume due to low reaction rate, high investment cost, process vulnerability, and low resilience to inhibitors accumulation are still pending for more research works on this process [3]. Additionally, to facilitate its final disposal, anaerobically digested sludge is generally dewatered after coagulation/flocculation, targeting easily dewatering and energysaving. The decrease of water content in dewatered sludge can largely reduce its volume thus lowering energy consumption and treatment costs during the downstream processes including transportation. Moreover, in WWTPs almost $50 \%$ of the total operational cost is contributed by sludge management, especially the sludge dewatering unit which usually consumes a large amount of expensive chemicals [4]. The high cost of sludge management is becoming a big issue for the sustainable management of WWTPs, especially in developing regions and countries.

Biogranulation is a phenomenon that microbial cells are self-aggregated into dense and rapid settling granules, beneficial for the separation of treated liquid from sludge particles [5]. Up-flow anaerobic sludge blanket (UASB) is currently the most popular anaerobic granular sludge (AnGS) system, which has many advantages such as low energy consumption, moderate capital and operating costs, low biomass yield, and high tolerance to toxic substances [5], [6]. The UASB reactor, developed by Lettinga and his colleagues in the late 1970s, was firstly and successfully utilized in a beet sugar refinery in the Netherlands [7], [8]. Now the UASB systems have been popularly applied in the treatment of high strength industrial wastewaters containing phenolic compounds [6] and those from food processing [9], potato-starch [10], etc. If there's no acclimatized (granular) sludge, the start-up of UASB is usually performed by seeding anaerobically digested sludge [7], [11], [12] or septic tank sludge [13] together with the feeding of organic wastewaters. In general, the seed sludge used for granulation should possess appropriate stability and density in addition to high methanogenic activity, which is usually required to be acclimated and cultivated at first under anaerobic condition. Nevertheless, it is always difficult to find enough anaerobically digested sludge to quickly start up a full-scale AnGS system. As known, the digested sludge is the effluent sludge from the anaerobic digester treating sewage sludge like primary sludge, waste activated sludge, and/or their mixture. Sewage sludge containing a large amount of organic matters is considered as the potential alternative to organic wastewater for UASB in this study. After being anaerobically treated, the digested sludge might be further functioned as the seed of UASB for further granule formation. An early study by Wu et al. [14] shows that activated sludge can be used as seed to start up the granulation in UASB treating prepared glucose molasses solution and citrate wastewater. In this study, a new concept was put forward regarding whether sludge stabilization and granulation could be achieved simultaneously during the treatment of sewage sludge by UASB. The first quick and important step to take with this new concept was probably to examine the possibility of using an AnGS system for sewage sludge treatment. Up to the present, however, little information is available on the use of granular UASB to treat sewage sludge.

As pointed out by Bhunia and Ghangrekar [13], the upward shear force is crucial for sludge granulation in UASB, which is mainly determined by the liquid and biogas up-flow velocity, and the concentration of inoculum in the reactor. A successful start-up and stable operation of UASB can be achieved at hydraulic retention time $(\mathrm{HRT})<6 \mathrm{~h}$. In the stable AD system of sewage sludge, the feedstock, i.e., sewage sludge (instead of wastewater) input velocity can't provide a sufficient 
upward shear force due to its long HRT of $>10$ days [15]. Therefore, how to provide a suitable biogas up-flow condition to create enough upward shear force for sludge granulation under a long HRT condition is the key to the successful UASB operation for sewage sludge treatment.

On the other hand, biogas recirculation can not only provide mixing power but also achieve biogas upgrading for AD systems of organic solid wastes, which has been evidenced previously [16], [17], [18], [19]. Latha et al. [16] claimed that an optimum intermittent biogas recirculation was more promising as an alternative mixing method for the large-scale $\mathrm{AD}$ with low power consumption, as it could enhance biogas yield and improve energy efficiency when compared to the conventional mixing mode of impeller. Moreover, Yuan et al. [18], [20] and Zhao et al. [21] found that biogas upgrading and sludge conditioning could be simultaneously achieved during the AD of sewage sludge treatment under biogas recirculation coupled with $\mathrm{Fe}^{3+}[18], \mathrm{Mg}^{2+}$ [20], or $\mathrm{Ca}^{2+}$ [21] addition, reflecting its great potentials and profits for cost-saving sewage sludge management. In fact, biogas recirculation has been successfully applied in UASB systems treating various wastewaters, achieving accelerated reactor start-up with the generation of well settleable granular sludge [11], enhanced biomass retention efficiency [22], and promoted formation of microbial granules [23] as well. In this study, it's hypothesized that a suitable biogas recirculation may provide enough upward shear force for the granular UASB reactor to treat sewage sludge, which can maintain the whole reactor performance and produce digested sludge with better properties, especially in terms of sludge settleability and dewaterability. As such, it's necessary to pay more attention to the changes of AnGS and digested sludge in the granular UASB.

Therefore, in this study, a sewage sludge treatment system, i.e., granular UASB coupling with biogas recirculation was proposed, which is expected to maintain biological metabolisms through the dense anaerobic aggregates even under harsh conditions and improve the dewaterability of digested sludge simultaneously for sustainable management of sewage sludge. This work examined the possibility of using the biogas recirculation-driven granular UASB system to treat sewage sludge. More specifically, the effect of biogas recirculation on the granular sludge system performance was mainly concerned in addition to the changes in properties of AnGS and digested sludge so as to elucidate their roles in this system.

\section{Materials and methods}

\subsection{Sludge samples}

AnGS used as inoculum in this study was sampled from Asahi Beer Brewery in Ibaraki Prefecture, Japan. Concentrated primary sludge was obtained from the Shimodate WWTP in Ibaraki Prefecture, Japan. The total solids (TS) and volatile solids (VS) (based on wet weight) of AnGS and primary sludge were $5.79 \pm 0.28 \%$ and $3.77 \pm 0.35 \%(\mathrm{VS} / \mathrm{TS}=0.65)$, and $2.16 \pm 0.02 \%$ and $1.88 \pm 0.02 \%$ $(\mathrm{VS} / \mathrm{TS}=0.87)$, respectively. The water content of each sludge was equal to $100 \%$ minus TS $(\%)$. In this study, in order to facilitate samples analysis and calculation especially for the subsequent separation of digested sludge from AnGS, the primary sludge was sieved by a $0.5 \mathrm{~mm}$ sieve to remove some large particles, and the AnGS was sieved by the same $0.5 \mathrm{~mm}$ sieve to remove the small particulate substances that may not belong to AnGS according to the definition by Alphenaar [24]. Similarly, the size of AnGS was defined physically larger than $0.5 \mathrm{~mm}$ in this study. 


\section{2. $U A S B$ reactors}

Two identical UASB reactors (biogas-R1 and biogas-R2, in parallel) were fabricated as similar as in the previous study [21], each with an effective volume of $402 \mathrm{~mL}(\mathrm{D} \times \mathrm{H}=40 \mathrm{~mm} \times 320 \mathrm{~mm})$. To realize biogas recirculation, each UASB reactor was equipped with a gas flow meter and a gas pump. A gas collector was used to store a certain amount of biogas, and the biogas volume was quantified by displacing the saturated $\mathrm{NaHCO}_{3}$ solution in order to avoid the dissolution of $\mathrm{CO}_{2}$ in water. During biogas recirculation, the produced biogas was recirculated into the bottom of the UASB reactor through a microporous ceramic gas sparger, which was controlled by a preset timer and conducted intermittently ( 1 h-on/1h-off) at a constant flow rate of $25 \mathrm{~mL} / \mathrm{min}$ (with a resultant up-flow velocity of $2 \mathrm{~cm} / \mathrm{min}$ ) according to the preliminary experiments. The third reactor (control), with the same dimension and a gas collector but no other installations, was also set up and used for the $\mathrm{AD}$ of sewage sludge without biogas recirculation. The three reactors were operated at $37 \pm$ $2{ }^{\circ} \mathrm{C}$ in batch-mode $\mathrm{AD}$ experiments simultaneously.

Before being used as the feedstock, the primary sludge $\mathrm{pH}$ was adjusted to $\sim 9.0$ using a combination alkali addition strategy $\left(\mathrm{NaOH}\right.$ and $\left.\mathrm{Ca}(\mathrm{OH})_{2}\right)$ at a resultant added $\mathrm{Ca}^{2+}$ concentration of $300 \mathrm{mg} \mathrm{Ca} / \mathrm{L}$-sludge, an appropriate $\mathrm{Ca}^{2+}$ concentration that could stimulate the formation of granules during the start-up of UASB [25]. The inoculum (AnGS) and feedstock (primary sludge) were mixed at a ratio of 0.29 (VS basis), and the concentrations of AnGS and primary sludge in the reactors were 5.8 and $19.8 \mathrm{~kg} \mathrm{VS} / \mathrm{m}^{3}$-reactor, respectively, according to the properly inoculated sludge concentration recommended by Lettinga [26] and Lin and Yang [27]. The initial water content of the sludge mixture loaded into the reactor was about $96.8 \%$. After being fed with 400 $\mathrm{mL}$ of the sludge mixture, each reactor was purged with $\mathrm{N} 2$ gas for $5 \mathrm{~min}$ to create an anaerobic condition. Generally, biogas produced from the AD process mainly consists of $50-60 \% \mathrm{CH}_{4}$ and $40-50 \% \mathrm{CO}_{2}$, in addition to small amounts of other gases like $\mathrm{NH}_{3}, \mathrm{H}_{2} \mathrm{~S}, \mathrm{H}_{2}, \mathrm{CO}$, and $\mathrm{N}_{2}$ [17]. In order to rapidly initial the whole AD system, it was assumed that the AD system had been stably operated for a long time with enough biogas containing normal contents of $\mathrm{CH}_{4}$ and $\mathrm{CO}_{2}$ in the gas collector. Thus, in this study, synthetic biogas consisting of $60 \% \mathrm{CH} 4$ and $40 \% \mathrm{CO}_{2}$ was firstly injected into the gas collector with an initial biogas volume of $300 \mathrm{~mL}$ to start the biogas recirculation at the beginning of the $\mathrm{AD}$ process. During the whole operation, the biogas volume in the gas collector was maintained at the range of $300-600 \mathrm{~mL}$ by discharging the produced biogas manually from the gas outlet with a gas-tight injector due to the continuous biogas production. This operation could also ensure the same pressure inside the gas collector during the whole operation period, which approximated to the atmospheric pressure as determined. All the experiments were conducted in triplicate with the similar phenomenon being observed.

During the operation, the sludge was sampled periodically from the AD reactor after well mixed by biogas recirculation. The digested sludge and AnGS were separated carefully as soon as possible through the $0.5 \mathrm{~mm}$ sieve. Then a certain amount of digested sludge was taken for further analysis of the related parameters and the remaining digested sludge and AnGS were returned to the reactor right after the separation. At the end of the experiments, after the separation of AnGS from digested sludge, the AnGS on the $0.5 \mathrm{~mm}$ sieve was washed with distilled water for three times; then the separated digested sludge and AnGS were used for related analysis. 


\subsection{Analytical methods}

The biogas composition, i.e., $\mathrm{CH} 4$ and $\mathrm{CO} 2$ and their contents were determined by GC-8A gas chromatography (Shimadzu, Japan) equipped with a stainless-steel column packed with Porapak$\mathrm{Q}$ and a thermal conductivity detector connected to a chromatopac data analyzer (Shimadzu CR4A, Japan), and N2 was used as the carrier gas. Volatile fatty acids (VFAs) including acetic acid, propionic acid, iso-butyric acid, n-butyric acid, iso-valeric acid and n-valeric acid were determined by GC-14B gas chromatography (Shimadzu, Japan) equipped with Unisole F-200 30/60 column and ame ionization detector (FID). A pH meter (FE20, Mettler Toledo, Switzerland) and a conductivity meter (AS710, As One Co., Japan) were respectively used to measure the digested sludge sample $\mathrm{pH}$ and conductivity immediately right after being sampled. The measurements of TS and VS were carried out by drying the sample at $105^{\circ} \mathrm{C}$ to a constant weight first and then burning at $600{ }^{\circ} \mathrm{C}$ for $3 \mathrm{~h}$. Sludge surface charge was determined with the colloid titration technique, and polybrene and polyvinyl sulphate (PVSK) were respectively used as the standard cationic and anionic colloids as described previously [28]. In brief, the sludge sample collected from the AD reactor was firstly diluted with distilled water and then mixed with excess $0.001 \mathrm{~N}$ polybrene solution with a small amount of toluidine blue $(0.1 \mathrm{~mL}$ used in this study) added as the color indicator. Then the above mixture was titrated against $0.001 \mathrm{~N}$ PVSK till a subtle color change from blue to pink/purple, signaling its electrical neutrality.

Sludge extracellular polymeric substances (EPS) were extracted and quantified according to Yuan et al. [20] with slight modifications by using distilled water instead of $0.05 \% \mathrm{NaCl}$ as the resuspension solution to avoid the influence of cations determination. Soluble EPS (S-EPS) were directly extracted from the sludge sample by centrifugation at $5000 \mathrm{rpm}$ for $10 \mathrm{~min}$; after being washed for three times, the sediment was then re-suspended using distilled water for the followedup extraction. The loosely bound EPS (LB-EPS) were extracted after the sample being heated at $70{ }^{\circ} \mathrm{C}$ for $1 \mathrm{~min}$ and centrifuged at $5000 \mathrm{rpm}$ for $10 \mathrm{~min}$. Again, being washed with distilled water for three times, the re-suspended mixture was heated at $60{ }^{\circ} \mathrm{C}$ for $30 \mathrm{~min}$ and centrifuged at $5000 \mathrm{rpm}$ for $15 \mathrm{~min}$. The resultant supernatant was collected to determine the concentration of tightly bound EPS (TB-EPS). The concentrations of proteins and polysaccharides in the extracted EPS were measured using the Lowry method and phenol-sulfuric acid method, respectively, with bovine serum albumin and glucose as the respective standards. Cations $\left(\mathrm{Na}^{+}, \mathrm{K}^{+}, \mathrm{Mg}^{2+}\right.$, and $\left.\mathrm{Ca}^{2+}\right)$ in the extracted EPS were quantified by ion chromatography (Shimadzu, Japan).

In this study, capillary suction time (CST) of digested sludge measured by a CST meter (CST-1, Yamato Scientific Co., Ltd., Japan) was used to evaluate the sludge dewaterability. A smaller CST value indicates better sludge dewaterability. The settling velocity of granules was determined by monitoring the falling of granules in tap water [12]. Granular strength was measured by determining the TS distribution in the supernatant and the remaining part after being shaken at 200 $\mathrm{rpm}$ for $5 \mathrm{~min}$ [12]. The proportion of TS in the supernatant could indicate the strength of the granules: the smaller value, the greater the granular strength. Morphology of granules was observed with Leica M205 C Microscope (Leica Micro-systems, Switzerland). The granular size distribution was estimated by image analysis according to Tassew et al. [29] assisted by Leica M205 C Microscope but with a simplified procedure, in which the diameter of granules was estimated by vernier caliper with the granules being assumed to be spherical. 
In addition, the effects of biogas recirculation on electron transport system (ETS) activity during the AD of sewage sludge was assessed using the reduction method of 2-(p-iodophenyl)-3-(pnitrophenyl)-5-phenyltetrazolium chloride (INT) to formazan (INTF) according to Zhang et al. [30].

\subsection{Statistical analysis}

The statistical difference of the experimental data was analyzed by an independent sample t-test using SPSS 17.0 software, and $\mathrm{p}<0.05$ was considered statistically significant.

\section{Results and discussion}

\subsection{Performance of the up-flow granular sludge systems}

\subsection{1. $\mathrm{CH}_{4}$ production}

Fig. 1A illustrates the cumulative $\mathrm{CH}_{4}$ production and $\mathrm{CH}_{4}$ content from the reactors during the 24 days' $\mathrm{AD}$ operation. The $\mathrm{CH}_{4}$ contents in the reactors with biogas recirculation (biogas- $\mathrm{R} 1$ and -R2, in parallel) significantly increased during the AD process compared to the control, achieving biogas upgrading as similar as previous studies [19], [20], [21]. The average $\mathrm{CH}_{4}$ contents in the control, biogas-R1, and -R2 during the whole operation were $76.2 \pm 2.2 \%, 83.6 \pm 4.2 \%$, and $84.5 \pm 2.5 \%$, respectively. Although the same cumulative $\mathrm{CH}_{4}$ production was obtained from the three UASB reactors at the end of the tests, the two biogas recirculation-driven UASB systems progressed much faster. In this study, kinetic models including the first-order, modified Gompertz, and Cone kinetic models were adopted to fit and evaluate the UASB of sewage sludge, which have been widely applied for the AD process [31]. The experimental $\mathrm{CH}_{4}$ yields were fitted to the above three kinetic models, with the data fitting and the meanings of the corresponding parameters being shown in Table 1. As seen, the modified Gompertz and Cone models exhibited a higher correlation coefficient $\left(\mathrm{R}^{2}\right)$, lower residual sum of squares, and lower Diff. value in comparison to the firstorder model, indicating their better fit to the $\mathrm{CH}_{4}$ production process of sewage sludge under the test conditions. Compared to the control, a much higher specific rate constant $(\mathrm{k}$, increased by 80 $100 \%)$ from the Cone model and maximum $\mathrm{CH}_{4}$ production rate $(\mu$, increased by $31-44 \%)$ from the modified Gompertz model were obtained in the two biogas recirculation systems. This observation suggests that biogas recirculation could shorten the duration time of the AD process thus favored organic matter degradation and $\mathrm{CH}_{4}$ production. As seen from Table 1, the lag-phase duration $(\lambda)$ of the control reactor, about 2.4 days, was shortened to $0.08-0.2$ day in the biogas recirculation systems according to the modified Gompertz model, signaling the desirable condition for the $\mathrm{AD}$ of sewage sludge under the test biogas recirculation. This observation also implies that biogas recirculation could facilitate the quick start-up of the granular UASB system. The increased $\mathrm{CH}_{4}$ production rate and shortened lag-phase duration via biogas recirculation could be attributable to various aspects, such as the promoted contact and interaction between substrates and microorganisms [16], and the increased buffering capacity in the AD system, especially during the hydrolysis stage due to enhanced dissolution of $\mathrm{CO}_{2}$. Besides the functions of mixing and enhanced contact between the microorganisms and substrates induced by biogas recirculation, $\mathrm{CO}_{2}-$ containing biogas recirculation may be responsible for the enrichment of hydrogenotrophic methanogens and their enhanced activities [18], [32], resulting in better AD performance of biogas$\mathrm{R} 1$ and $-\mathrm{R} 2$. 

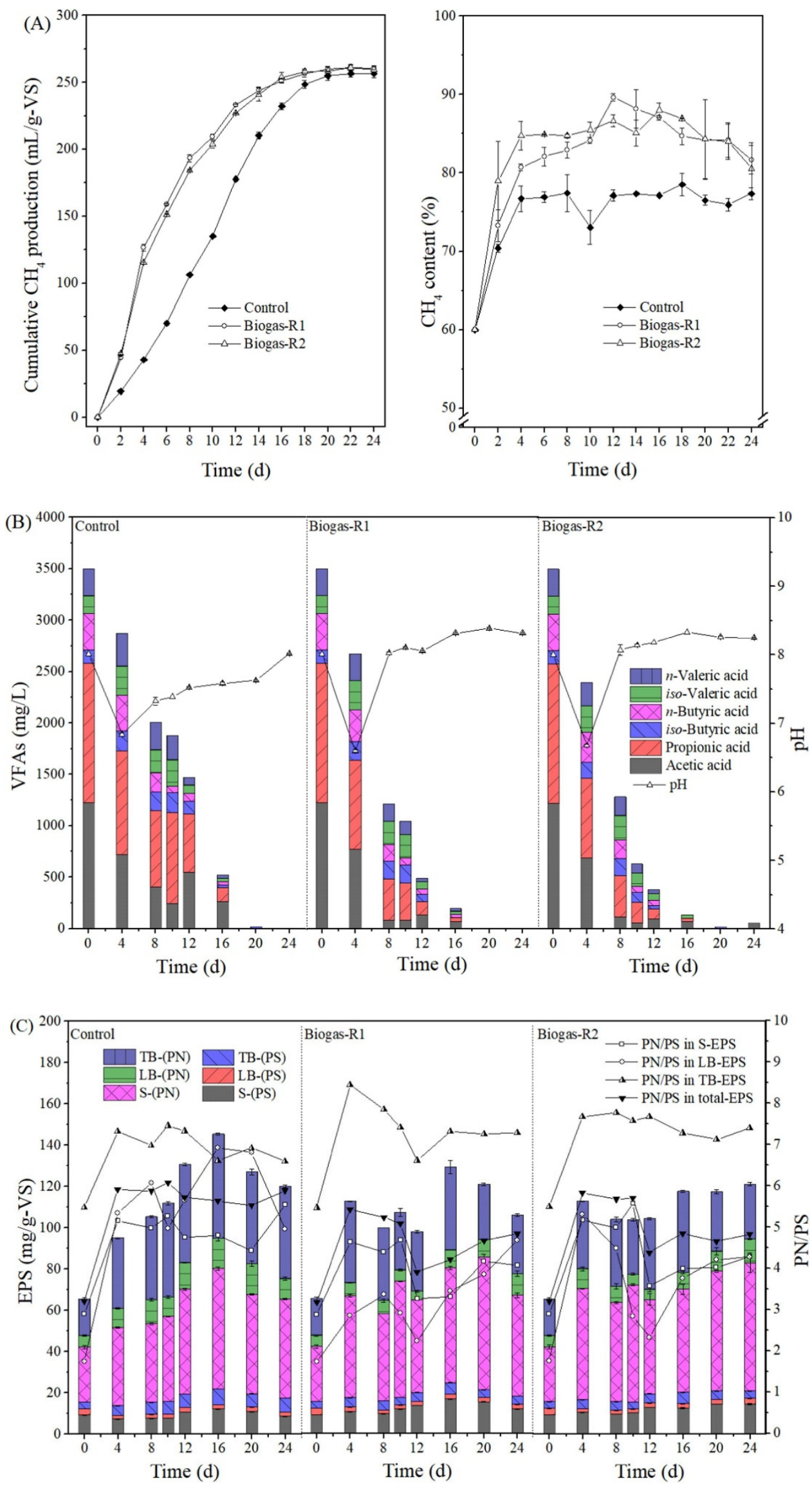

Fig. 1. Changes in (A) cumulative $\mathrm{CH}_{4}$ production and its content, (B) VFAs and $\mathrm{pH}$, and (C) EPS during the operation of UASB reactors. Control, with no biogas recirculation; Biogas-R1 and -R2, the two identical UASB under biogas recirculation (in parallel operation). 
Table 1. Kinetic models and related parameters estimated from the experimental data of the three UASB systems.

\begin{tabular}{|c|c|c|c|c|}
\hline Model & Parameter & Control & $\begin{array}{l}\text { Biogas- } \\
\text { R1 }\end{array}$ & $\begin{array}{l}\text { Biogas } \\
\text { R2 }\end{array}$ \\
\hline \multirow[t]{2}{*}{ Experimental value } & $\mathrm{G}_{\max 0}(\mathrm{~mL}$ & 256.37 & 260.3 & 259.46 \\
\hline & $\begin{array}{l}\mathrm{CH}_{4} / \mathrm{g}- \\
\left.\mathrm{VS}_{\text {fed }}\right)\end{array}$ & \pm 3.08 & \pm 2.12 & \pm 2.3 \\
\hline \multirow{10}{*}{$\begin{array}{l}\text { The first order } G(t)=G_{\max }[1- \\
\quad \exp (-k t)]\end{array}$} & $\mathrm{G}_{\max }(\mathrm{mL}$ & 298.65 & 275.83 & 280.24 \\
\hline & $\mathrm{CH}_{4} / \mathrm{g}-$ & \pm 73.36 & \pm 6.12 & \pm 5.59 \\
\hline & $\left.\mathrm{VS}_{\mathrm{fed}}\right)$ & & & \\
\hline & $k\left(d^{-1}\right)$ & $\begin{array}{l}0.06 \pm \\
0.03\end{array}$ & $\begin{array}{l}0.14 \pm \\
0.01\end{array}$ & $\begin{array}{l}0.13 \pm \\
0.01\end{array}$ \\
\hline & $\mathrm{R}^{2}$ & 0.908 & 0.990 & 0.994 \\
\hline & Reduced & 306.82 & 71.80 & 47.78 \\
\hline & $\begin{array}{l}\text { Chi- } \\
\text { Square }\end{array}$ & & & \\
\hline & Residual & 9630.71 & 789.84 & 525.58 \\
\hline & $\begin{array}{l}\text { Sum of } \\
\text { Squares }\end{array}$ & & & \\
\hline & Diff. value & 16.5 & 6.0 & 8.0 \\
\hline \multirow{15}{*}{$\begin{array}{l}\text { Modified Gompertz } G(t)=G_{\max } \\
\qquad \exp \left\{-\exp \left[\frac{\mu}{G_{\max }}(\lambda-t) e+1\right]\right\}\end{array}$} & $\mathrm{G}_{\max }(\mathrm{mL}$ & 277.04 & 257.89 & 260.21 \\
\hline & $\mathrm{CH}_{4} / \mathrm{g}-$ & \pm 6.34 & \pm 4.54 & \pm 4.42 \\
\hline & $\left.\mathrm{VS}_{\mathrm{fed}}\right)$ & & & \\
\hline & $\mu\left(\mathrm{mLCH}_{4} /\right.$ & $19.47 \pm$ & 28.08 & 25.55 \\
\hline & $g-V S / d)$ & 0.94 & \pm 2.25 & \pm 1.78 \\
\hline & $\lambda(\mathrm{d})$ & $2.42 \pm$ & $0.20 \pm$ & $0.08 \pm$ \\
\hline & & & & \\
\hline & $\mathrm{R}^{2}$ & 0.996 & 0.988 & 0.990 \\
\hline & Reduced & 40.99 & 90.60 & 72.38 \\
\hline & Chi- & & & \\
\hline & Square & & & \\
\hline & Residual & 409.99 & 906.05 & 723.84 \\
\hline & Sum of & & & \\
\hline & Squares & & & \\
\hline & Diff. value & 8.1 & 0.9 & 0.3 \\
\hline \multirow{14}{*}{ Cone $G(t)=\frac{G_{\max }}{1+(k t)^{-n}}$} & $\mathrm{G}_{\max }(\mathrm{mL}$ & 310.35 & 283.41 & 293.51 \\
\hline & $\mathrm{CH}_{4} / \mathrm{g}-$ & \pm 19.85 & \pm 6.49 & \pm 7.82 \\
\hline & $\left.\mathrm{VS}_{\mathrm{fed}}\right)$ & & & \\
\hline & $\mathrm{k}\left(\mathrm{d}^{-1}\right)$ & $0.10 \pm$ & $0.20 \pm$ & $0.18 \pm$ \\
\hline & & 0.01 & 0.01 & 0.01 \\
\hline & $\mathrm{n}$ & $2.21 \pm$ & $1.68 \pm$ & $1.57 \pm$ \\
\hline & & 0.24 & 0.11 & 0.10 \\
\hline & $\mathrm{R}^{2}$ & 0.992 & 0.996 & 0.997 \\
\hline & Reduced & 79.06 & 27.31 & 24.43 \\
\hline & Chi- & & & \\
\hline & Square & & & \\
\hline & Residual & 790.62 & 273.13 & 244.31 \\
\hline & $\begin{array}{l}\text { Sum of } \\
\text { Squares }\end{array}$ & & & \\
\hline & Diff. value & 21.1 & 8.9 & 13.1 \\
\hline
\end{tabular}

Note: $\mathrm{G}\left(\mathrm{mL} \mathrm{CH}_{4} / \mathrm{g}\right.$-VS), cumulative specific methane production; $\mathrm{G}_{\max }\left(\mathrm{mL} \mathrm{CH}_{4} /\right.$ $\mathrm{g}$-VS), ultimate methane production; $\mathrm{k}\left(\mathrm{d}^{-1}\right)$, specific rate constant; $\mathrm{t}(\mathrm{d})$, digestion duration; $\mu$ ( $\mathrm{mL} \mathrm{CH}_{4} / \mathrm{g}$-VS/d), maximum methane production rate; $\lambda$ (d), lag-phase duration; $\mathrm{e}=2.7182 ; n$, dimensionless shape factor.

Diff. value is the absolute value of the difference between experimental value and modified value of maximum $\mathrm{CH}_{4}$ yield. Diff. value $=100 \times \mid\left(\mathrm{G}_{\max 0}-\right.$ $\left.\mathrm{G}_{\max }\right) \mid / \mathrm{G}_{\max 0}$. 


\subsubsection{Changes in VFAs and $\mathrm{pH}$}

The AD process mainly consists of four steps: hydrolysis, acidogenesis, acetogenesis, and methanogenesis. Among the four steps, hydrolysis is regarded as the rate-limiting one [4] that can decompose complex organic substances into soluble monomers. In the acidogenesis step, soluble monomers can be further converted into intermediate products like VFAs [33]. Thus, the changes in $\mathrm{pH}$ and VFAs concentration in the reactors were monitored during the AD process as shown in Fig. 1B. The initial feedstock (i.e., primary sludge) was initially adjusted to $\sim \mathrm{pH} 9.0$, but this $\mathrm{pH}$ value dropped to $\sim 8.0$ within two hours during the loading into the AD reactor with high VFAs being detected on day 0 simultaneously because of alkaline hydrolysis. During the AD process, the $\mathrm{pH}$ value dropped sharply during the first 4 days from the same initial $\mathrm{pH}(\sim 8.0)$, followed by a gradual increase and finally to a relatively stable value. In general, VFAs accumulation would result in a sharp $\mathrm{pH}$ drop and this phenomenon lasted to day 4 , and on day 8 the $\mathrm{pH}$ value was detected to gradually increase with continuous decline of VFAs concentration. Obviously, the lowest $\mathrm{pH}$ did not correspond to the highest VFAs on day 4, which might occur during day 0 to day 4. Being different from the control (no biogas recirculation, $\mathrm{pH}=6.83 \pm 0.02$ ) on day 4 , the $\mathrm{pH}$ values in the biogas recirculation UASB systems were a little bit lower, averagely $6.74 \pm 0.05$, which is attributable to the 40 times higher water solubility of $\mathrm{CO}_{2}$ than $\mathrm{CH}_{4}$ [16] and the increase in contact time between $\mathrm{CO}_{2}$ and digestate under biogas recirculation. The dissolution of $\mathrm{CO}_{2}$ in the digestate might remarkably decrease the bulk liquor $\mathrm{pH}$ [34]. However, $\mathrm{CO}_{2}$-containing biogas recirculation may also form a carbonate buffer system [35] which brings about the accumulation of alkalinity in the AD system as previously reported [19]. More specifically, during the whole operation, a lower VFAs accumulation in the biogas recirculation reactors was always detected when compared to the control. The enhanced carbonate buffer capacity in the biogas recirculationdriven UASB reactors may play a key role in their stable operation [19], and they were also detected to have higher $\mathrm{pHs}$ and lower VFAs accumulation during the remaining operation period (excepting the first 4 days). Therefore, the performance of granular UASB could be enhanced due to the improvement of hydrolysis via enhanced $\mathrm{CO}_{2}$ dissolution together with the carbonate buffering system.

\subsubsection{Changes in EPS extracted from digested sludge}

EPS consisting of variable proportions of proteins (PN) and polysaccharides (PS) are an important part of the sludge biomass, which can influence the matrix structure and stability of granular sludge to a great extent [36]. EPS may protect the cell-matrix and resist the adverse influence of the environment with their composition being dependent on the nature of aggregates [37]. PN and PS are also the intermediates in the AD process, which are produced during the hydrolysis and acidogenesis steps, and then consumed in the acidogenesis and acetogenesis steps [38]. During the $\mathrm{AD}$ of sewage sludge, EPS were extracted from the digested sludge and quantified as shown in Fig. $1 C$. As seen, no significant difference $(p>0.05)$ in the amount of total-, LB-(PS)-, and S-(PN)EPS, while a significant difference $(p<0.05)$ in the amount of S-(PS)-, TB-(PS)-, LB-(PN)-, and TB-(PN)-EPS was noticed in the digested sludge between the control and biogas recirculation systems. A higher S-(PS)-EPS, and lower TB-(PS)-, LB-(PN)-, and TB-(PN)-EPS contents were detected in biogas-R1 and -R2 when compared to the control. It is known that PN are mainly localized in the core region of the granules, while PS are easy to loosen from the EPS in the presence of upward shear force, which may negatively affect the sludge granulation [9], [39]. Being 
different from the traditional UASB reactors treating high strength organic wastewater under the combined shear force from hydraulic and biogas uplifting, the UASB reactors in this study were applied for sewage sludge stabilization only under the shear force from biogas recirculation. In this process, the sludge particles may possess the potentials to form granular sludge, during which organic matters including PN and PS from sludge are degraded simultaneously. Therefore, the amount and components of EPS in the sludge may be different from the formation process of granular sludge, which are influenced by the degree of sludge degradation and other factors. Moreover, the PN/PS ratio in EPS may indicate the formation and stabilization of granular sludge [9]. As claimed by Hulshoff Pol et al. [40], a high proportion of PN is favorable for sludge granulation because of its high negatively charged amino acids. Basuvaraj et al. [39] stated that the PN/PS ratio should be about 1.4 for granular sludge with a good settleability. In this study, the $\mathrm{PN} / \mathrm{PS}$ ratios in TB-EPS were obviously higher in the digested sludge from biogas-R1 and -R2 compared to the control, while their S- and LB-EPS were lower than the control, implying that the relative degradation degrees of PN and PS were different in different layers of sludge particles, or there might be some movement of PN towards the central layer. In addition, the relative higher PN in the central layer of sludge particles from the biogas recirculation UASB systems may favor the formation of new granules. Still, more in-depth works should be conducted, including the changes in PN and PS types and their properties that are crucial for the sludge granulation process and particle stability.

\subsubsection{Changes in sludge surface charge, conductivity, and ETS activity}

Fig. 2A and B show the changes in sludge surface charge and conductivity during the operation of UASB systems. A significant difference $(p<0.05)$ was found in both sludge surface charge and conductivity between the biogas recirculation systems (biogas-R1 and -R2) and the control. Compared to the control (with no biogas recirculation), the sludge from the biogas recirculation systems showed relatively lower negative surface charge and conductivity.
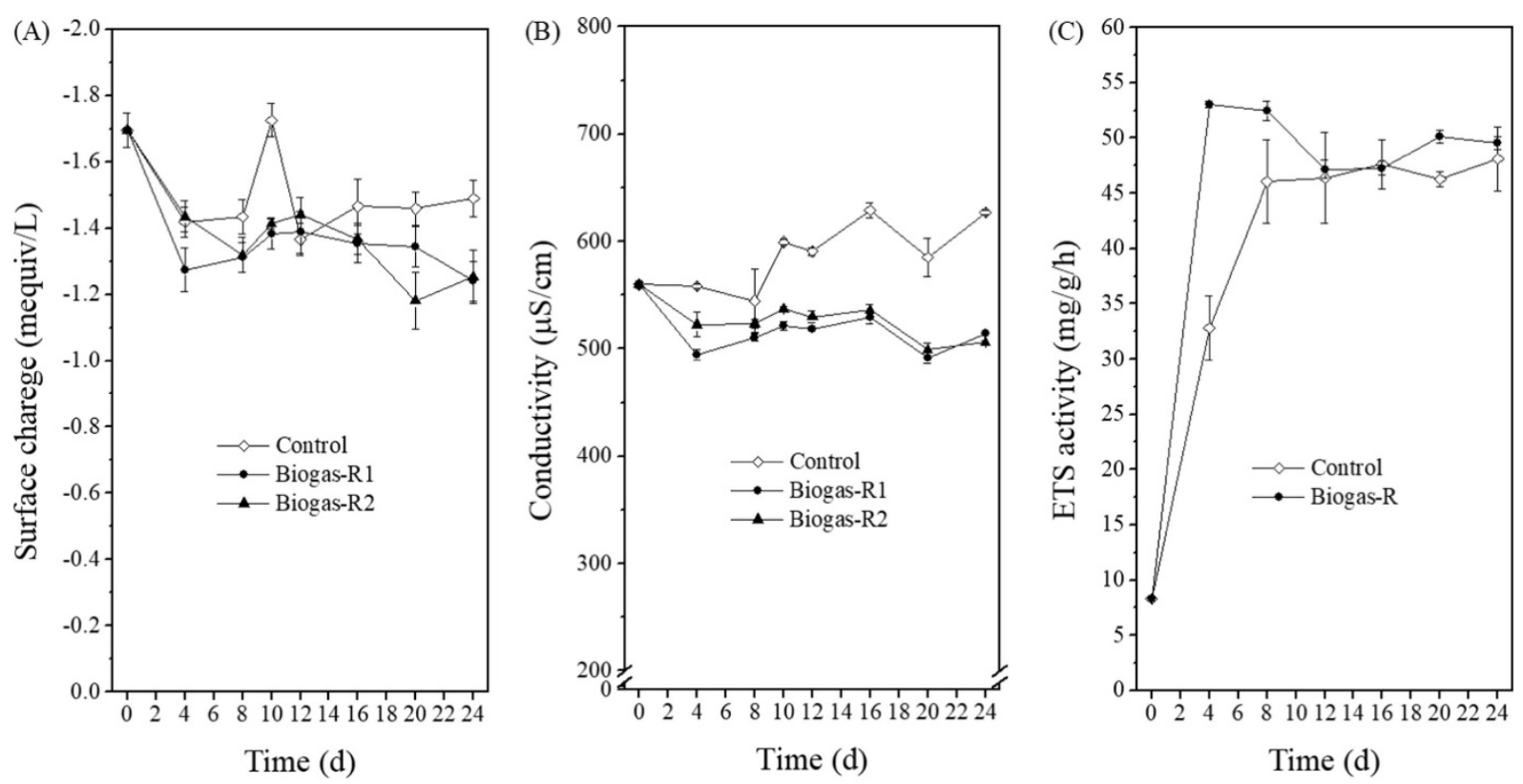

Fig. 2. Changes in (A) surface charge, (B) conductivity, and (C) electron transport system (ETS) activity during the operation of UASB reactors. Control, with no biogas recirculation; Biogas-R1 and -R2, the two identical UASB under biogas recirculation (in parallel operation); Biogas-R, one 
reactor for repeated experiments of biogas recirculation $\mathrm{AD}$ system operated under the same conditions as for biogas-R1 and -R2

Sludge surface charge has long been believed to be closely associated with the stability of microbial aggregates [36]. In general, the surface of sludge particles is negatively charged, which may gradually decrease along with the formation of granules [41]. Granular sludge was also found to be less negatively charged than activated sludge [28]. During the AD process, the presence of some cations such as $\mathrm{Ca}^{2+}$ could enhance microbial adhesion through compressing the electrical double layers on the cell surface and linking exocellular polymers [25]. Most recently, Liang et al. [6] found that $\mathrm{Ca}^{2+}$ may reduce electrostatic repulsion between negatively charged bacteria, which can also bind to EPS accelerating bacterial adhesion. The formed microbial aggregates may have the potential to further form granules due to the biogas upward shear force. Therefore, in this biogas recirculation-driven granular UASB system (using AnGS as inoculum) for sewage sludge treatment, a positive tendency to form granular sludge was observed during the $\mathrm{AD}$ of sewage sludge.

The conductivity of microbial aggregates can reflect the ability of microorganisms to transport electrons, which is beneficial for $\mathrm{AD}$ [42], especially for the direct interspecies electron transfer within flocs or granular microbial aggregates [43]. At the end of AD operation, the conductivity of digested sludge in the control was higher than that in the biogas recirculation systems (biogas-R1 and -R2, Fig. 2B), indicating a worsening ability of sludge to transport electrons under biogas recirculation. On the contrary, a better $\mathrm{AD}$ performance was obtained in the two biogas recirculation systems (Section 3.1.1), probably due to more interspecies electron transfer occurred within the granules or sludge flocs (not in the bulk solution used for conductivity determination). Another possible reason for this phenomenon might be associated with some soluble cations that also greatly influence the determination of conductivity. Clearly seen, much lower soluble cations were detected in the biogas recirculation systems (biogas-R1 and -R2, Fig. 3A), and a significant correlation at the 0.01 level was noted between the conductivity and soluble total cations, probably leading to the lower conductivity of sludge. The effect of soluble cations on conductivity might be greater than the interspecies electron transfer within the granules or sludge flocs, resulting in the contradictory observations between the AD performance and bulk conductivity. Therefore, the ETS activity of digested sludge was determined in this study to further explain this phenomenon.

The ETS activity can more intuitively reflect the activity of the electron transfer in microorganisms, namely, the electron transport efficiency [30]. In this study, as shown in Fig. 2C, initially the ETS activity increased rapidly in all the reactors, which was consistent with the occurrence of methanogenic processes. A higher ETS activity was always detected in the biogas recirculation UASB system, especially during the first 8 days, which was approximately 1.62 times on day 4 and 1.14 times on day 8 that of the control reactor, further confirming that the ETS activity is closely associated with biogas production rate. Consequently, the better AD performance, lower negative surface charge and conductivity, and higher ETS activity in the biogas recirculation UASB systems indicated that more interspecies electron transfer occurred within sludge flocs or granules under the test biogas recirculation conditions. 

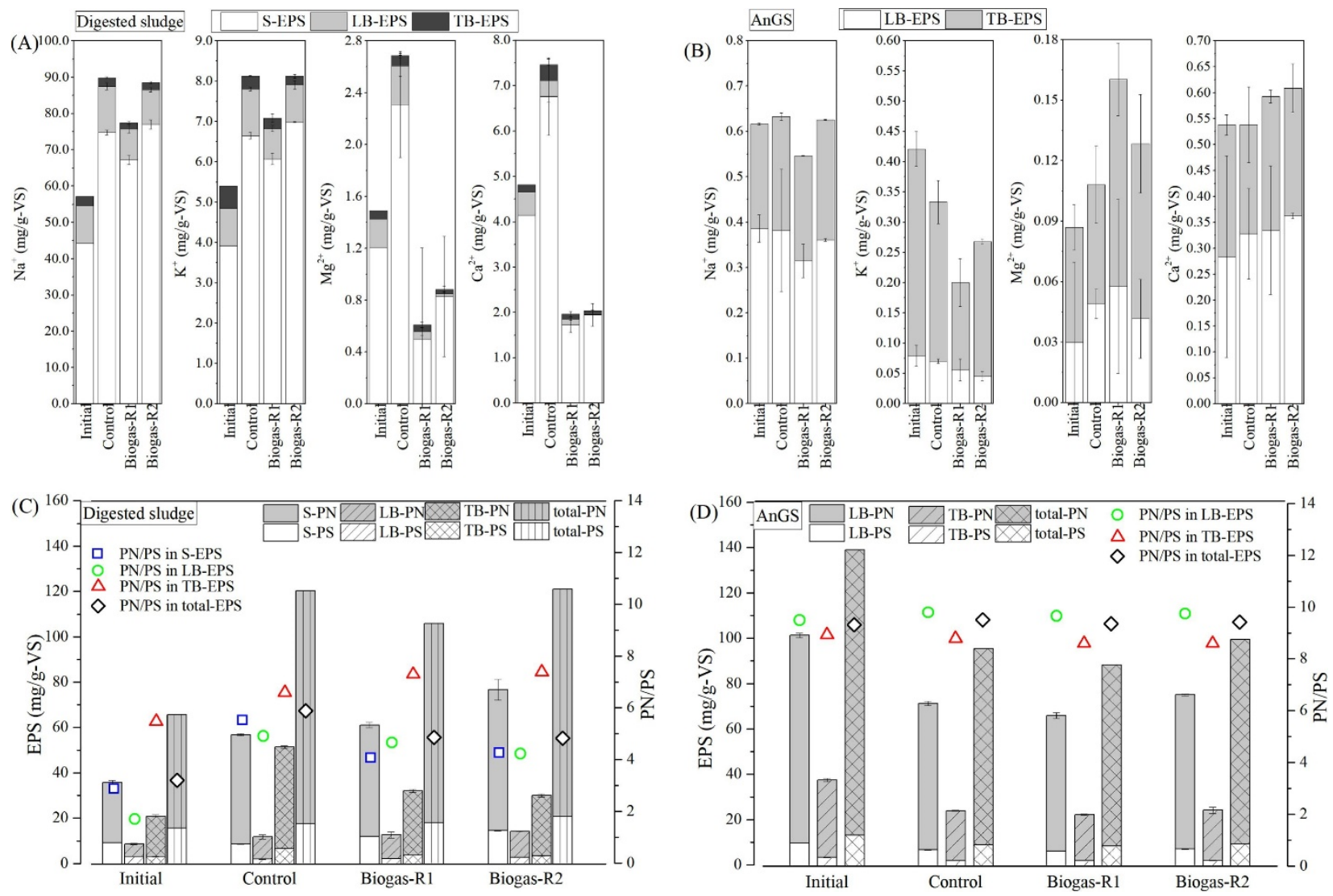

Fig. 3. Changes in concentrations of cations $\left(\mathrm{Na}^{+}, \mathrm{K}^{+}, \mathrm{Mg}^{2+}\right.$, and $\left.\mathrm{Ca}^{2+}\right)(\mathrm{A}$ and $\mathrm{B})$, proteins (PN) and polysaccharides (PS) (C and D) in EPS extracted from digested sludge and anaerobic granular sludge (AnGS), respectively.

In this work, the biogas recirculation-driven granular UASB for sewage sludge treatment was operated in batch mode for a short time (24 days) with one-off feeding of sewage sludge. As a consequence, this operation might have limited detectable effects on the granulation of digested sludge. But its existing influence could not be ignored, particularly on the betterment of sludge dewaterability that will be discussed in Section 3.3. It is expected to achieve granular digested sludge (at least the digested sludge with strong self-aggregation ability) after a long-term operation of the biogas recirculation-driven granular UASB during the treatment of sewage sludge, which demands further exploration and confirmation in the followed-up experiments.

\subsection{Comparison of AnGS and digested sludge from $U A S B$ reactors}

It has been reported that the formation of granular sludge plays a crucial role in the maintenance of stable process and performance of UASB during wastewater treatment [9]. In this study, the UASB reactor was applied to treat sewage sludge, and biogas recirculation instead of hydrodynamic shear force from influent wastewater provided the upward shear force. To better evaluate the changes in sludge properties during the AD operation under biogas recirculation, the digested sludge (with AnGS being removed) and the AnGS were separated and analyzed comparatively at the end of the AD experiments.

\subsubsection{Cations in EPS}


Generally, sludge flocs or sludge particles are composed of multivalent cations, EPS, microorganisms, biogenic and inorganic substances, etc., in which cations play a vital role in sludge stability and dewaterability. Besides, cations may help accelerate the granulation process through bridging between negatively charged groups on cell surfaces and linking the exocellular polymers [25]. Therefore, the changes of cations in EPS might have some implication for this sludge treatment system. As shown in Fig. 3A, after the AD process, the concentrations of cations including $\mathrm{Na}^{+}, \mathrm{K}^{+}, \mathrm{Mg}^{2+}$, and $\mathrm{Ca}^{2+}$ in the total EPS increased in the digested sludge from the control reactor, while $\mathrm{Na}^{+}$and $\mathrm{K}^{+}$increased but $\mathrm{Mg}^{2+}$ and $\mathrm{Ca}^{2+}$ decreased in the digested sludge from the biogas recirculation systems (biogas-R1 and -R2) when compared to their initial values. The decreases in $\mathrm{Mg}^{2+}$ and $\mathrm{Ca}^{2+}$ concentrations may be associated with their changes in S-EPS, reflecting more $\mathrm{Mg}^{2+}$ and $\mathrm{Ca}^{2+}$ uptake by microbes or their combination with some inorganics or organics (via precipitation or conjugation), which is conductive to microbial cells self-aggregation or sludge re-flocculation. In contrast, as shown in Fig. 3B, the amount of cations in the extracted EPS from AnGS was much less and relatively stable than that from digested sludge, indicating the better stability of AnGS than digested sludge and some difficulty of cations release from granules. Less cations were detected to release during the extraction of EPS with relatively long error bars for the data from $>3$ times batch extraction experiments, however, the same trend was observed for the same batch extraction. For instance, no obvious difference was noticed in the concentration of $\mathrm{Na}^{+}$in AnGS between the control and biogas recirculation systems; a lower $\mathrm{K}^{+}$concentration was detected in the EPS of AnGS from the biogas recirculation systems (biogas-R1 and -R2) which contained higher $\mathrm{Mg}^{2+}$ and $\mathrm{Ca}^{2+}$ concentrations in comparison to the control. It is clearly evidenced that the presence of divalent ions, such as $\mathrm{Ca}^{2+}$ and $\mathrm{Mg}^{2+}$, is a key factor for sludge granulation [12], [44]. Results from this study show that $\mathrm{Mg}^{2+}$ and $\mathrm{Ca}^{2+}$ can be further accumulated in the EPS of AnGS, especially $\mathrm{Ca}^{2+}$ that has been found to effectively speed up the granulation process and be extensively accumulated in the microbial aggregates [25], [45], which would also improve granular strength. In this study, the strength of all the AnGS was below $0.8 \%$ with no significant difference among the test reactors (Fig. 5A), suggesting the very strong and stable granules in this study. As reported, the uptake of $\mathrm{Mg}^{2+}$ and $\mathrm{Ca}^{2+}$ by the sludge might be beneficial for sludge granulation during wastewater treatment, while the higher uptake of $\mathrm{Na}^{+}$and $\mathrm{K}^{+}$may adversely influence sludge concentration, granular strength, sludge settling velocity, and treatment efficiency. This is inferred from the fact that more uptake of $\mathrm{Na}^{+}$and $\mathrm{K}^{+}$might have saturated carrier molecules, thus restricting the uptake of $\mathrm{Mg}^{2+}$ and $\mathrm{Ca}^{2+}$ [12]. Up to the present, still, limited information could be found regarding the effects of various cations contained in the sewage sludge on its anaerobic granulation during the $\mathrm{AD}$ process, which needs more in-depth studies.

\subsubsection{Organic matters in EPS}

As discussed in Section 3.1.3 and shown in Fig. 3C, the changes in EPS from digested sludge at the end of the $\mathrm{AD}$ experiments suggest its potential for granule formation in the biogas recirculation systems. Compared to the digested sludge, no significant change in the EPS from AnGS was noticed for the control and biogas recirculation systems after the AD process (Fig. 3D). This observation implies that biogas recirculation exerted little influence on the composition of EPS from AnGS. It is known that PS are hydrophilic polymers, while PN, especially the amino acids in PN, contribute to the hydrophobic character of flocs [39]. Since the large number of negatively charged amino acids contained in PN can form electrostatic bonds with multivalent cations, the aggregate structure may become stable [46]. EPS can help promote the adhesion of microorganisms 
through chemical bonds or physical entanglement, and the granules with a higher TB-EPS content usually possess better mechanical strength and physical stability [9], [39]. In this study, the high $\mathrm{PN} / \mathrm{PS}$ ratio in the TB-EPS from digested sludge together with little change in the EPS from AnGS, as well as the decrease of $\mathrm{Ca}^{2+}$ content in digested sludge and the accumulation of $\mathrm{Ca}^{2+}$ in AnGS suggest the great potential of sewage sludge to form aggregates and even granules in the granular UASB system under biogas recirculation condition.

\subsubsection{Changes in dewaterability of digested sludge}

As shown in Fig. 4, a better dewaterability of digested sludge indicated by a lower CST was detected in both biogas recirculation systems (biogas-R1 and -R2). To exclude the effect of TS on CST, the CST value based on TS content was also calculated, which shows the similar trend. Basuvaraj et al. [39] claimed that LB- and TB-EPS control the floc behavior, and PN-rich TB-EPS extracted from granular sludge contribute to the improvement of sludge dewaterability. In this study, a high PN/PS in TB-EPS was noticed in the biogas recirculation systems, which is probably the main reason for better sludge dewaterability. Besides, the multivalent cations may condense the diffusion within the electrical double layers, promoting the aggregation of microbial pellets due to Van der Waals forces [25]. $\mathrm{Ca}^{2+}$ may also play a major role in the resultant better sludge dewaterability, indicative of less soluble $\mathrm{Ca}^{2+}$ in the biogas recirculation systems because of the aggregation or bridging between $\mathrm{Ca}^{2+}$ and organics like PN.

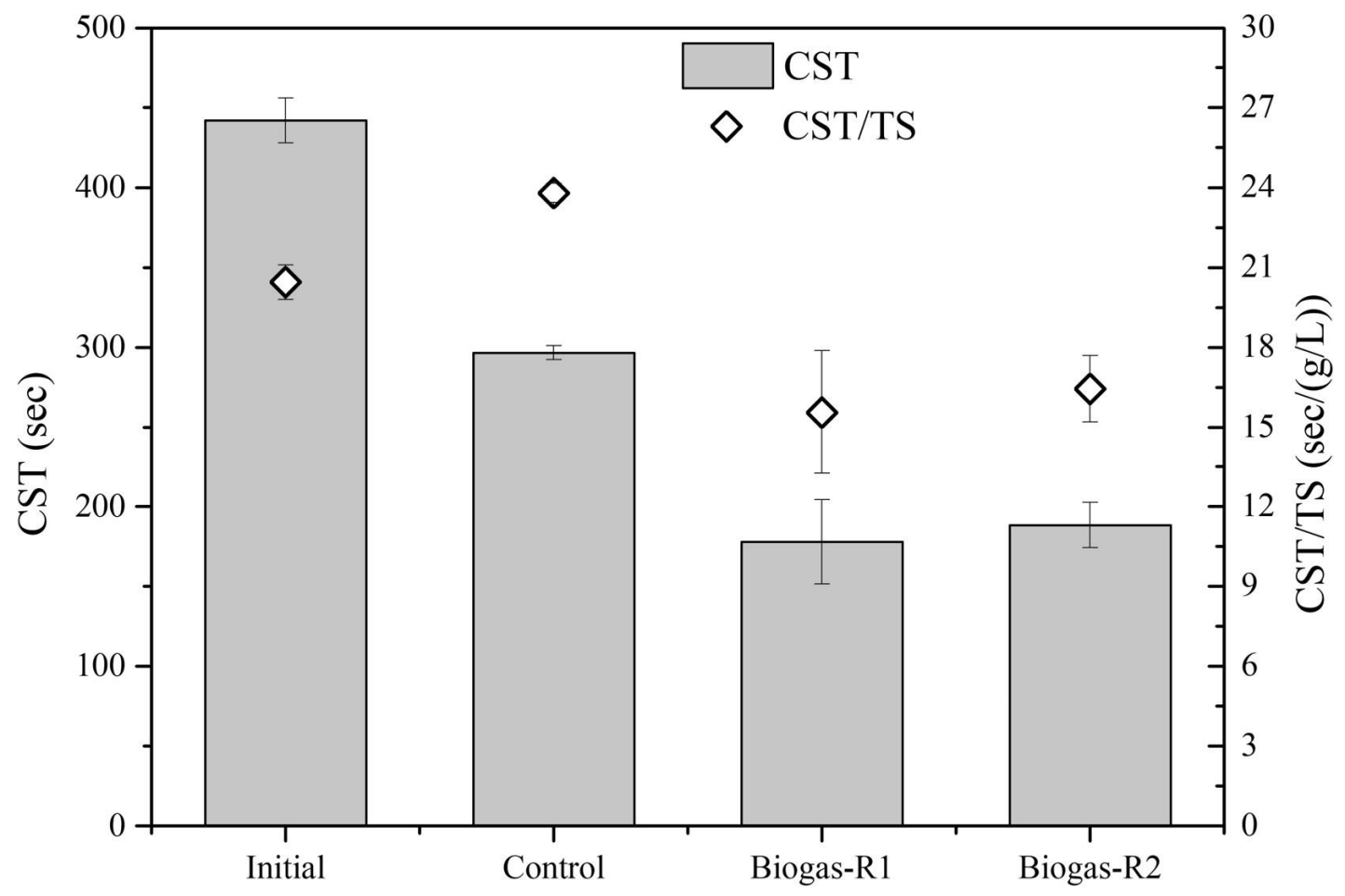

Fig. 4. Sludge dewaterability indicated by capillary suction time (CST) of digested sludge at the initial and the end of the AD process. Initial, sampled primary sludge; Control, with no biogas recirculation; Biogas-R1 and -R2, the two identical granular UASB with biogas recirculation (in parallel operation).

\subsection{Changes in the characteristics of AnGS}


AnGS was collected from the UASB reactors before and after batch AD tests to check their characteristics in terms of granular strength, VS/TS, particle size distribution, settling velocity, and morphology.

\subsubsection{Granular strength and biomass content}

Granular strength is a key parameter to characterize the sludge quality. Granules with higher strength could resist the upward shear force, while the granules with lower strength might break up and cause biomass loss thus worsening the reactor performance [47]. In this study as shown in Fig. $5 \mathrm{~A}$ and $\mathrm{B}$, the applied AnGS was very strong with little changes in granular strength $(<0.8 \%)$ and $\mathrm{VS} / \mathrm{TS}$ ratio being noticed under the test conditions, indicating that biogas recirculation had no obvious effect on granular strength and biomass content in AnGS.
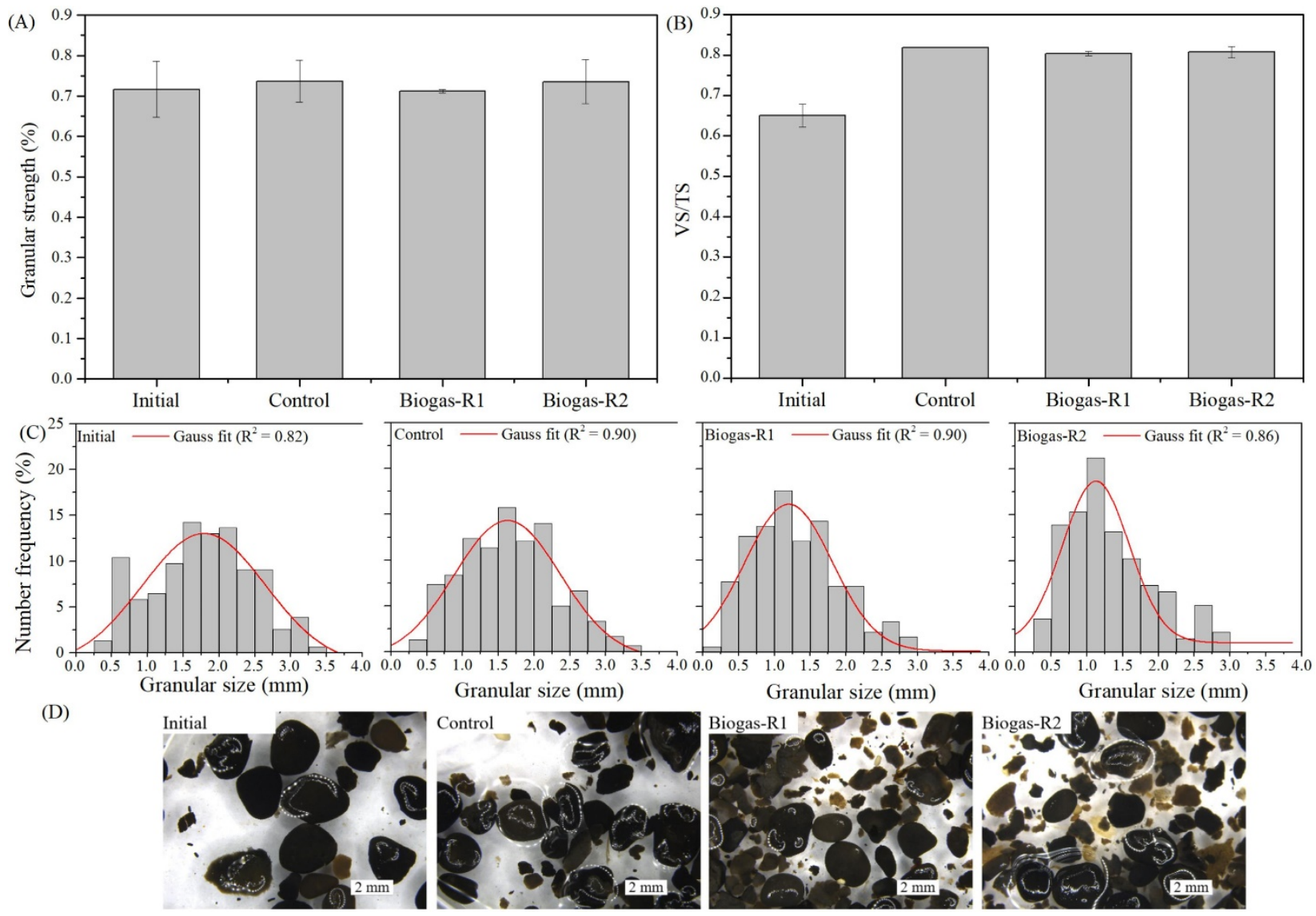

Granular size $(\mathrm{mm})$

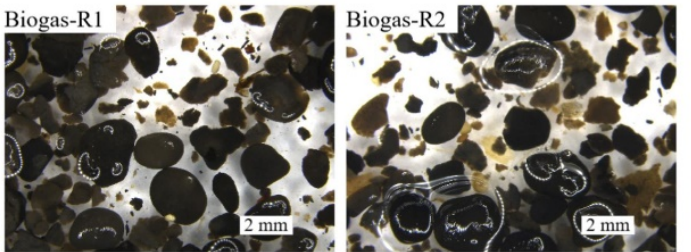

Fig. 5. Changes in granular strength (A), VS/TS ratio (B), granular size distribution (C), and morphology (D) of anaerobic granular sludge (AnGS) at the initial and the end of the AD process. Initial, seed AnGS; Control, with no biogas recirculation; Biogas-R1 and -R2, the two identical granular UASB under biogas recirculation.

\subsubsection{Size distribution}

The size distribution demonstrates that the granules were normally distributed, which could be well fitted by the Gauss model $\left(\mathrm{R}^{2}>0.82\right)$. As shown in Fig. $5 \mathrm{C}$ and $\mathrm{D}$, after 24 days' operation, the main granule size decreased from the initial AnGS with a main size of 1.50-2.25 mm to 1.25-2.00 $\mathrm{mm}$ in the control and to $0.75-1.50 \mathrm{~mm}$ in biogas-R1 and -R2. As mentioned in Section 2.1, in this study the granular sludge is physically defined as sludge particles with size $>0.5 \mathrm{~mm}$ [24]. It can 
be seen from Fig. $5 \mathrm{C}$ that the proportion of $>0.5 \mathrm{~mm}$ particles accounted for $98.7 \%, 98.7 \%, 91.8 \%$, and $96.4 \%$ in the initial, control, biogas-R1, and -R2, respectively. The main granular size became slightly smaller with a slower settling velocity in the biogas recirculation systems that are probably not beneficial for the maintenance of stable operation of larger-scale granular systems. This phenomenon may also indicate the dynamic breakage and growth of granular sludge, which needs further confirmation after a long-term operation of the biogas recirculation-driven granular UASB. Hulshoff Pol et al. [40] claimed that the upward shear force is not responsible for breaking or disintegrating the granules, and only the growth of small particles may change the size distribution of granules. Therefore, the granular size distribution in the UASB reactors is probably brought about by the growth of small aggregates which may be potentially developed into larger granules. In this regard, these small size aggregates might start a new generation of growth nuclei, further promoting anaerobic granulation [6], in which the attachment of cells to these particles is proposed as the initiation step for granulation.

\subsection{A proposal for economically sustainable sludge management}

The energy recovered from the AD of sewage sludge in WWTPs can be partially utilized for biogas recirculation in the granular UASB system. Namely, the produced biogas can be used to power an electricity generator that is operated to provide power for biogas recirculation, heating digesters, and dewatering of the digested sludge. $\mathrm{CH}_{4}$ in-situ enrichment can be obtained by biogas recirculation thus improving the heating value of biogas [19]. The amount of energy generation from produced biogas, and energy consumption including heating the digesters and powering the gas pumps in the control, biogas-R1, and -R2 systems can be estimated based on the operation data of a local WWTP (Ibaraki, Japan) as described in detail in Supplementary Materials. As shown in Table 2, the biogas recirculation-driven granular UASB can improve net energy profit by $78-85 \%$ from sewage sludge treatment compared to the control (traditional AD system). In addition, much less or no other chemical addition is required during the dewatering of digested sludge due to its better sludge dewaterability and formation of compact and dense granular structure in the UASB system. The current UASB system achieved 37-40\% improvement on sludge dewaterability compared to the control, which could be further enhanced after the optimization of operational conditions including biogas recirculation rate, organic solids loading, temperature, etc. As summarized by Wei et al. [48], 37-98\% improvement of sludge dewatering could be achieved using chemical or organic flocculants. This biogas recirculation-driven UASB system is expected to realize no additional chemical addition and energy self-sufficiency for sustainable sewage sludge management under its optimal operation conditions. The findings from this work are valuable for sludge management in full-scale WWTPs, which still needs more in-depth research especially on the long-term operation of continuous-flow sewage sludge treatment systems. A key challenge to the successful development of granules is the long start-up time of the bioreactors. This work proved that microbial cells' self-aggregation or sludge re-flocculation of digested sludge could be achieved by this system, which is an important step in the formation of anaerobic granules. Therefore, more detailed research works are still demanding to further explore the possibility of granule formation from digested sludge in this biogas recirculation-driven granular UASB during the long-term treatment of sewage sludge. 
Table 2. Energy balance analysis of the three UASB systems.

\begin{tabular}{llll}
\hline UASB system & Control & Biogas-R1 & Biogas-R2 \\
\hline $\mathrm{CH}_{4}$ content $(\%)$ & 76.2 & 83.6 & 84.5 \\
LHVbiogas $\left(\mathrm{MJ} / \mathrm{m}^{3}\right)$ & 26.51 & 28.04 & 28.26 \\
The peak brake thermal efficiency $(\eta, \%)$ & 28.9 & 32.2 & 32.7 \\
Energy generated from biogas $(\mathrm{MJ} / \mathrm{t})$ & 87.19 & 102.80 & 105.18 \\
$\tau$ (days) & 13.96 & 8.79 & 9.39 \\
Energy consumption for heating $(\mathrm{MJ} / \mathrm{t})$ & 71.79 & 65.95 & 66.63 \\
Energy consumption by gas pump $(\mathrm{MJ} / \mathrm{t})$ & 0 & 9.39 & 10.03 \\
Net energy profit from UASB system $(\mathrm{MJ} / \mathrm{t})$ & 15.40 & 27.46 & 28.52 \\
\hline
\end{tabular}

Note: $\mathrm{LHV}_{\text {biogas }}$, lower heating value of biogas; $\tau$, effective $\mathrm{CH}_{4}$ production duration, i.e., the time used to produce $80 \%$ of the total $\mathrm{CH}_{4}$ production.

\section{Conclusions}

A biogas recirculation granular UASB system was applied to treat sewage sludge. Biogas recirculation can help mix the influent sludge and provide biogas upward shear force with simultaneous achievement of biogas upgrading. Compared with the control (no biogas recirculation), the $\mathrm{CH}_{4}$ production rate in the biogas recirculation system was enhanced by $31-44 \%$ with lag-phase duration shortened to $0.08-0.2$ day, which was mainly ascribed to the improvement of interspecies electron transfer. Almost no obvious effect of biogas recirculation on the granular characteristics was observed, excepting some decrease in granule size. Besides, the digested sludge with $37-40 \%$ better dewaterability may be attributed to the self-aggregation of microbial cells induced by biogas recirculation. Therefore, the results from this work can help establish a sewage sludge treatment system which can couple biogas recirculation with granular sludge system to achieve biogas upgrading and easily dewatered digested sludge with no additional chemical addition. This work can also provide an innovative technique for the enhancement of energy recovery from sewage sludge.

\section{Acknowledgements}

This work was supported by JSPS KAKENHI Grant Numbers JP18H03403 and JP16H06382. Ms. Jiamin Zhao would like to thank the financial support by the China Scholarship Council for her PhD study at University of Tsukuba, Japan.

\section{References}

[1] Lam CM, Hsu SC, Alvarado V, Li WM. Integrated life-cycle data envelopment analysis for technoenvironmental performance evaluation on sludge-to-energy systems. Appl Energ 2020; 266: 114867.

[2] MLIT (Ministry of Land, Infrastructure, Transport and Toursim), Japan, https://www.mlit.go.jp/mizukokudo/sewerage/crd_sewerage_tk_000124.html; 2020 [accessed 10 April 2021].

[3] Di Capua F, Spasiano D, Giordano A, Adani F, Fratino U, Pirozzi F, et al. High-solid anaerobic digestion of sewage sludge: Challenges and opportunities. Appl Energ 2020; 278: 115608. 
[4] Zhen G, Lu X, Li Y-Y, Zhao Y. Combined electrical-alkali pretreatment to increase the anaerobic hydrolysis rate of waste activated sludge during anaerobic digestion. Appl Energ 2014; 128: 93102.

[5] Show K-Y, Yan Y, Yao H, Guo H, Li T, Show D-Y, et al. Anaerobic granulation: A review of granulation hypotheses, bioreactor designs and emerging green applications. Bioresour Technol 2020; 300: 122751.

[6] Liang J, Wang Q, Yoza BA, Li QX, Chen C, Ming J, et al. Rapid granulation using calcium sulfate and polymers for refractory wastewater treatment in up-flow anaerobic sludge blanket reactor. Bioresour Technol 2020; 305: 123084.

[7] Lettinga G, van Velsen AFM, Hobma SW, de Zeeuw W, Klapwijk A. Use of the upflow sludge blanket (USB) reactor concept for biological wastewater treatment, especially for anaerobic treatment. Biotechnol Bioeng 1980; 22: 699-734.

[8] Lim SJ. Comparisons between the UASB and the EGSB reactor, http://home.eng. iastate.edu/ tge/ce421-521/seungjoo.pdf; 2009 [accessed 10 April 2021].

[9] Chen H, Wei Y, Xie C, Wang H, Chang S, Xiong Y, et al. Anaerobic treatment of glutamate-rich wastewater in a continuous UASB reactor: Effect of hydraulic retention time and methanogenic degradation pathway. Chemosphere 2020; 245: 125672.

[10] Luo G, Wang W, Angelidaki I. A new degassing membrane coupled upflow anaerobic sludge blanket (UASB) reactor to achieve in-situ biogas upgrading and recovery of dissolved CH4 from the anaerobic effluent. Appl Energ 2014; 132: 536-42.

[11] Jayantha KS, Ramanujam TK. Start-up criteria for a upflow anaerobic sludge blanket (UASB) reactor. Bioprocess Eng 1995; 13: 307-10.

[12] Ghangrekar MM, Asolekar SR, Joshi SG. Characteristics of sludge developed under different loading conditions during UASB reactor start-up and granulation. Water Res 2005; 39: 1123-33.

[13] Bhunia P, Ghangrekar MM. Influence of biogas-induced mixing on granulation in UASB reactors. Biochem Eng J 2008; 41: 136-41.

[14] Wu W, Hu J, Gu X, Zhao Y, Zhang H, Gu G. Cultivation of anaerobic granular sludge in UASB reactors with aerobic activated sludge as seed. Water Res 1987; 21: 789-99.

[15] Appels L, Baeyens J, Degr`eve J, Dewil R. Principles and potential of the anaerobic digestion of waste-activated sludge. Prog Energ Combust 2008; 34: 755-81.

[16] Latha K, Velraj R, Shanmugam P, Sivanesan S. Mixing strategies of high solids anaerobic codigestion using food waste with sewage sludge for enhanced biogas production. J Clean Prod 2019; 210: 388-400.

[17] Mahmoodi-Eshkaftaki M, Houshyar E. Biogas recirculation technology: Effect on biogas purification, slurry characteristics, microbial activity and energy consumption. Environ Technol Innov 2020; 19: 100867.

[18] Yuan T, Wang Y, Nuramkhaan M, Wang X, Zhang Z, Lei Z, et al. Coupling biogas recirculation with $\mathrm{FeCl} 3$ addition in anaerobic digestion system for simultaneous biogas upgrading, phosphorus conservation and sludge conditioning. Bioresour Technol 2020; 315: 123811.

[19] Zhao J, Hou T, Lei Z, Shimizu K, Zhang Z. Effect of biogas recirculation strategy on biogas upgrading and process stability of anaerobic digestion of sewage sludge under slightly alkaline condition. Bioresour Technol 2020; 308: 123293. 
[20] Yuan T, Cheng Y, Wang X, Yu Y, Zhang Z, Lei Z, et al. A novel anaerobic digestion system coupling biogas recirculation with $\mathrm{MgCl} 2$ addition for multipurpose sewage sludge treatment. $\mathrm{J}$ Clean Prod 2019; 230: 499-507.

[21] Zhao J, Hou T, Lei Z, Shimizu K, Zhang Z. Performance and stability of biogas recirculationdriven anaerobic digestion system coupling with alkali addition strategy for sewage sludge treatment. Sci Total Environ 2021; 783: 146966.

[22] Siddique NI, Munaim MSA, Wahid ZA. Role of biogas recirculation in enhancing petrochemical wastewater treatment efficiency of continuous stirred tank reactor. J Clean Prod 2015; 91: 229-34.

[23] Wei C, Zhang T, Feng C, Wu H, Deng Z, Wu C, et al. Treatment of food processing wastewater in a full-scale jet biogas internal loop anaerobic fluidized bed reactor. Biodegradation 2011; 22: 347-57.

[24] Alphenaar PA. Anaerobic Granular Sludge: Characterization, and Factors Affecting its Functioning. PhD dissertation. The Netherlands: Wageningen University; 1994. p. 5.

[25] Tiwari MK, Guha S, Harendranath CS, Tripathi S. Influence of extrinsic factors on granulation in UASB reactor. Appl Microbiol Biot 2006; 71: 145-54.

[26] Lettinga G. Anaerobic wastewater treatment based on biomass retention with emphasis on the UASB process. 4th Int'1 Symp on Anaerobic. Digestion 1985: 279-301.

[27] Lin KC, Yang Z. Technical review on the UASB process. Int J Environ Stud 1991; 39: 203-22.

[28] Morgan JW, Forster CF, Evison L. A comparative study of the nature of biopolymers extracted from anaerobic and activated sludges. Water Res 1990; 24: 743-50.

[29] Tassew FA, Bergland WH, Dinamarca C, Bakke R. Settling velocity and size distribution measurement of anaerobic granular sludge using microscopic image analysis. J Microbiol Meth 2019; 159: 81-90.

[30] Zhang F, Hou J, Miao L, Chen J, Xu Y, You G, et al. Chlorpyrifos and 3,5,6-trichloro-2-pyridinol degradation in zero valent iron coupled anaerobic system: Performances and mechanisms. Chem Eng J 2018; 353: 254-63.

[31] Villamil JA, Mohedano AF, Rodriguez JJ, De la Rubia MA. Anaerobic co-digestion of the aqueous phase from hydrothermally treated waste activated sludge with primary sewage sludge: A kinetic study. J Environ Manage 2019; 231: 726-33.

[32] Duarte MS, Sinisgalli E, Cavaleiro AJ, Bertin L, Alves MM, Pereira MA. Intensification of methane production from waste frying oil in a biogas-lift bioreactor. Renew Energ 2021; 168: $1141-8$.

[33] Li Y, Chen Y, Wu J. Enhancement of methane production in anaerobic digestion process: A review. Appl Energ 2019; 240: 120-37.

[34] Li Y-Y, Qiao W. Transformations and impacts of ammonia and hydrogen sulfide in anaerobic reactors. Anaerobic Biotechnology. Imperial College Press; 2015. p. 109-31.

[35] Yu D, Meng X, Liu J, Dian L, Sui Q, Zhang J, et al. Formation and characteristics of a ternary pH buffer system for in-situ biogas upgrading in two-phase anaerobic membrane bioreactor treating starch wastewater. Bioresour Technol 2018; 269: 57-66.

[36] Liu Y-Q, Liu Y, Tay J-H. The effects of extracellular polymeric substances on the formation and stability of biogranules. Appl Microbiol Biot 2004; 65: 143-8. 
[37] D’Abzac P, Bordas F, Van Hullebusch E, Lens PN, Guibaud G. Extraction of extracellular polymeric substances (EPS) from anaerobic granular sludges: Comparison of chemical and physical extraction protocols. Appl Microbiol Biot 2010; 85: 1589-99.

[38] Yin C, Shen Y, Dai X, Zhu N, Yuan H, Lou Z, et al. Integrated anaerobic digestion and CO2 sequestration for energy recovery from waste activated sludge by calcium addition: Timing matters. Energy 2020; 199: 117421.

[39] Basuvaraj M, Fein J, Liss SN. Protein and polysaccharide content of tightly and loosely bound extracellular polymeric substances and the development of a granular activated sludge floc. Water Res 2015; 82: 104-17.

[40] Hulshoff Pol LW, de Castro Lopes SI, Lettinga G, Lens PNL. Anaerobic sludge granulation. Water Res 2004; 38: 1376-89.

[41] Guo J, Kang Y. Characterization of sulfate-reducing bacteria anaerobic sludge granulation enhanced by chitosan. J Environ Manage 2020; 253: 109648.

[42] Li C, Lesnik KL, Liu H. Stay connected: Electrical conductivity of microbial aggregates. Biotechnol Adv 2017; 35: 669-80.

[43] Caiz'an-Juanarena L, ter Heijne A, Weijma J, Yntema D, Su'arez-Zuluaga DA, Buisman CJN. Screening for electrical conductivity in anaerobic granular sludge from full-scale wastewater treatment reactors. Biochem Eng J 2020; 159: 107575.

[44] McHugh S, O’Reilly C, Mahony T, Colleran E, O'Flaherty V. Anaerobic granular sludge bioreactor technology. Rev Environ Sci Biotechnol 2003; 2: 225-45.

[45] Abbasi T, Abbasi SA. Formation and impact of granules in fostering clean energy production and wastewater treatment in upflow anaerobic sludge blanket (UASB) reactors. Renew Sust Energ Rev 2012; 16: 1696-708.

[46] Laspidou CS, Rittmann BE. A unified theory for extracellular polymeric substances, soluble microbial products, and active and inert biomass. Water Res 2002; 36: 2711-20.

[47] Wang C, Liu Y, Gao X, Chen H, Xu X, Zhu L. Role of biochar in the granulation of anaerobic sludge and improvement of electron transfer characteristics. Bioresour Technol 2018; 268: 28-35.

[48] Wei H, Gao B, Ren J, Li A, Yang H. Coagulation/flocculation in dewatering of sludge: A review. Water Res 2018; 143: 608-31. 